\title{
Visual associative agnosia: a clinico-anatomical study of a single case
}

\author{
ROSALEEN A McCARTHY, ELIZABETH K WARRINGTON
}

From the National Hospital for Nervous Diseases, London, UK

SUMmARY A single case study of a patient with visual associative agnosia is described. The patient had well preserved language, spatial, visual, and perceptual abilities but nevertheless was impaired in recognising visually presented common objects. It is argued that his deficit cannot be accounted for in terms of a disconnection syndrome. Behavioural and anatomical (MRI scan) evidence for focal unilateral dysfunction is presented. It is concluded that the left hemisphere plays a crucial role in recognising the meaning of common objects.

Although impairment in the recognition of visually presented common objects with preserved perceptual skills may occur occasionally in the context of severe aphasia or dementia, it is very rarely observed as a selective deficit. Indeed convincing cases of visual associative agnosia have been so rare that its existence as a neurological syndrome has been disputed. ${ }^{1}$ In a retrospective analysis of over 400 cases of unilateral cerebral lesion Hecaen and Angelergues ${ }^{2}$ detected only one patient in whom the deficit was relatively selective and three further cases were noted in whom it occurred in the context of other severe cognitive impairments. De Renzi et al have reported a similar low incidence. ${ }^{3}$

Several cases of visual associative agnosia have been described in the literature; however, the majority have complicated additional disorders ${ }^{4-7}$ or extensive bilateral brain lesions. ${ }^{8-11}$ It is possible that there is only one case (although mild) of a unilateral lesion giving rise to this syndrome in its "pure" form. Hecaen et $a^{12}$ investigated quantitatively a patient who not only had some difficulty in naming common objects but was also impaired in describing their function, in demonstrating their use and in allocating them to a category of similar objects. He was also profoundly dyslexic. At the same time he was able to perform stringent perceptual tests (such as the Poppelreuter overlapping figures task) indicating that his visual processing capacity and perceptual analysis

Address for reprint requests: Dr RA McCarthy, Dept of Experimental Psychology, Downing St, Cambridge, UK.

Received 15 August 1985.

Accepted 28 September 1985 (apperception) was intact. This patient had a relatively large tumour occupying the posterior half of the left hemisphere.

We report our investigations of a patient with an associative visual agnosia in whom the lesion localisation was established precisely by MRI scanning. Our aim is to corroborate and extend the findings of Hecaen $e t$ al and to discuss the contibution of the left hemisphere to object recognition.

\section{Case report}

FRA was a right-handed 77 year-old retired shopkeeper. Apart from one undiagnosed episode of unconsciousness in 1975, he had been well until 1 March 1985 when he awoke and discovered that he was unable to read the newspaper. His dyslexia persisted and he was admitted to the National Hospital, Queen Square, under the care of Professor Gilliatt for investigation of his difficulties.

On examination his motor system was normal. However, he was noted to have a right homonymous hemianopia and a profound dyslexia. Serology, urea and liver function tests were normal as was his ECG. CT scan revealed a medial left occipital infarct which possibly involved the posterior temporal lobe. His MRI scan (fig 1) revealed a lesion in the lower part of the occipital lobe involving the white and grey matter. The medial occipital cortex and the fusiform and lateral occipital gyri were particularly affected. Sagittal images confirmed involvement of the inferior surfaces of the occipital lobe and occipital pole. The corpus callosum (including the splenium) and the cerebellum appeared normal. He was diagnosed as having sustained an infarction in the territory of the left posterior cerebral artery. His condition remained static and he was discharged home on 16 April 1985.

Psychological Test Findings

FRA's test scores are summarised in tables 1 and 2 . He was 

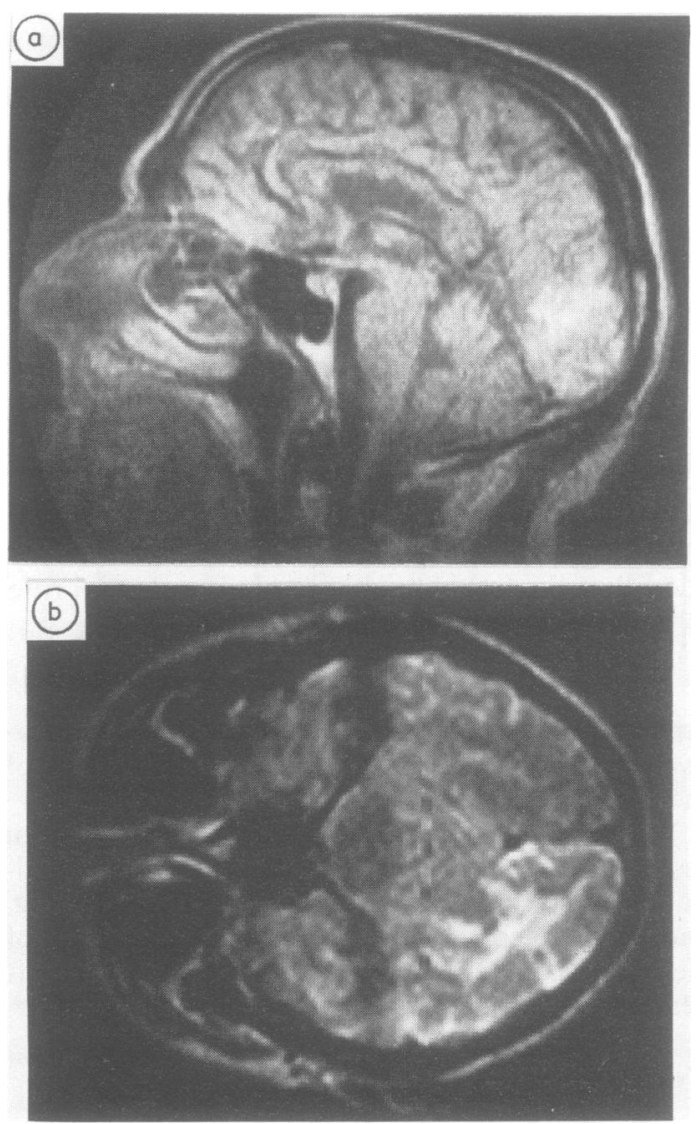

Fig 1 MRI scan showing infarction in the territory of the left posterior cerebral artery. (a) Sagittal view, (b) horizontal view.

able to function at an average level on the WAIS and to score satisfactorily on tests of memory. His expressive speech was fluent with appropriate content, vocabulary, syntax and prosody. He completely failed to recognise or name any items on the Graded Difficulty Naming test or the Oldfield pictures test. In contrast to his very poor per- formance on these two object naming tests his ability to name "action" pictures ${ }^{16}$ (for example digging, peeling, swimming) was remarkably good (50/60 correct). However, there was evidence of only very mild word-finding difficulties on auditory and oral tests (naming from description, verbal fluency), His identification of objects by touch (for example, corkscrew, tape measure, mitten) was relatively satisfactory.

His literacy skills were impaired having the characteristics of a total dyslexia with a mild dysgraphia. His naming of single letters was weak, though significantly better with tactile than with visual presentation (table 2). He was unable to recognise that a visually presented " $a$ " and an " $A$ " were the same letter. He attempted to read words by spelling them aloud but this strategy was completely vitiated by his letter recognition difficulties (indeed our corpus does not contain a single correct reading response). Furthermore, there was no evidence of his being able to comprehend even the commonest printed word. In contrast, his reading of arabic numerals was intact (table 2). His ability to write was considerably better than his reading; thus short common words and simple sentences were legibly and accurately produced to dictation. On a Graded Difficulty Spelling test using words which have unusual sound-spelling correspondences (for example "two", "flood", "sword") his score was low average (Baxter, personal communication). In this context it is of interest to note that his spelling of nonsense syllables was excellent (table 2).

There was no evidence of motor apraxia or constructional apraxia (fig 2). FRA had normal visual acuity (N6). His discrimination between a square and an oblong matched for total flux (Efron shapes), shape detection (presence or absence of a degraded " $\mathrm{X}$ "), and position discrimination (identification of centrally positioned dot in a square) were all intact (fig 3 and table 1). His ability to recognise photographs of famous personalities (selected from an array of three visually similar faces) was fairly satisfactory (table 1).

Despite the excellence of his visual and spatial abilities FRA reported difficulties in everyday life that suggested impaired object recognition. For example he stated that he frequently became muddled when attempting such simple tasks as setting a table. On word picture matching tests his performance was poor: thus he only scored at the 25th percentile on the Peabody Picture Vocabulary ${ }^{23}$ and on a revised version of this test which uses closely related distractor items (British Picture Vocabulary ${ }^{24}$ ), his score was very defective falling below the first percentile. There was also evidence of difficulties in colour recognition in so far as on a simple task of pointing to one of four named primary

Table 1 Verbal and non-verbal test scores.

\begin{tabular}{|c|c|c|c|c|}
\hline \multicolumn{3}{|l|}{ Verbal } & \multicolumn{2}{|l|}{ Non-verbal } \\
\hline $\begin{array}{l}\text { Verbal IQ } \\
\text { Arithmetic } \\
\text { Similarities } \\
\text { Digit Span } \\
\text { Vocabulary }\end{array}$ & $\begin{array}{l}\text { Raw. Score } \\
11 \\
9 \\
10 \\
45\end{array}$ & $\begin{array}{l}111 \\
\text { Age-Scaled } \\
13 \\
11 \\
12 \\
12\end{array}$ & $\begin{array}{l}\text { Performance IQ } \\
\text { P Completion } \\
\text { Block Design } \\
\text { P Arrangement }\end{array}$ & $\begin{array}{l}94 \\
\text { Age-Scaled } \\
10 \\
11 \\
7\end{array}$ \\
\hline $\begin{array}{l}\text { Forced-choice words }{ }^{13} \\
\text { Picture naming }{ }^{14} \mathrm{~s}^{3} \\
\text { Naming from description }{ }^{17} \\
\text { Fluency animals }\left(90^{\prime \prime}\right)^{17} \\
\text { Tactile identification }\end{array}$ & & $\begin{array}{l}34 / 50 \\
0 \\
9 / 15 \\
13 \\
32 / 40\end{array}$ & $\begin{array}{l}\text { Efron shapes }{ }^{19} \\
\text { Shape detection (adapted from ref 20) } \\
\text { Position discrimination } 21 \\
\text { Forced-choice famous faces } \\
\quad \text { (adapted from ref } 22 \text { ) }\end{array}$ & $\begin{array}{l}19 / 20 \\
30 / 30 \\
20 / 20 \\
19 / 30\end{array}$ \\
\hline
\end{tabular}


Table 2 Literacy Test Scores

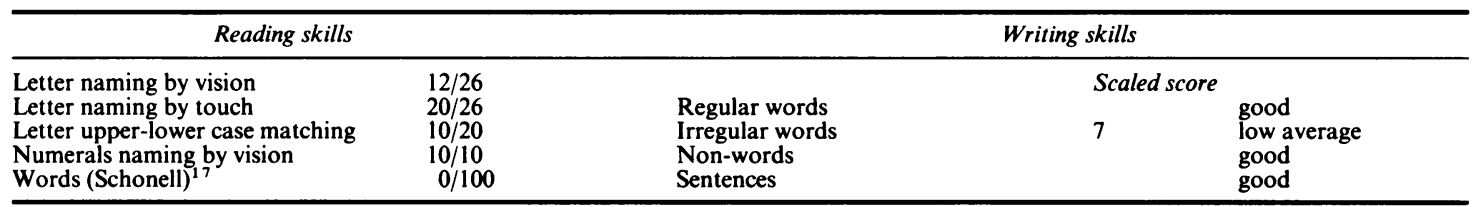

colours his performance was inaccurate. Since there was no evidence of any verbal comprehension impairment we would interpret these findings as probably being due to a deficit in visual recognition.

\section{EXPERIMENTAL INVESTIGATIONS}

Perceptual (apperceptive) tests

FRA's ability to achieve a coherently structured percept was investigated. He was able to trace 16/20 fragmented letters (despite failing to name any of them) indicating the ability to organise 2D stimuli (fig 3). His object perception was tested by presenting three figures from Poppelreuter's ${ }^{25}$ overlapping figures test, a task which is sensitive to apperceptive disorders. ${ }^{26}$ FRA was quite unable to name or recognise any of the individual items; however, when instructed to colour each object differently he performed the task effortlessly (fig 4). FRA's visual recognition impairment was so severe that many tests which manipulate visual complexity of pictured objects (for example Unusual Views, Unusual Lighting) were inappropriate. An alternative procedure was devised for varying perceptual difficulty: FRA was asked to point to named objects presented in arrays of six pictures of objects taken from children's picture vocabulary tests (for example Peabody). The objects were either depicted in isolation (for example cup) or in a visually complex scene (for example woman drinking). Each item was probed three times in arrays of simple, or complex pictures (fig 5). These conditions were ordered in an ABBA design. FRA scored $27 / 36$ in the "simple" condition and $28 / 36$ in the "complex". It is clear that (despite his significant $24 \%$ error rate) his
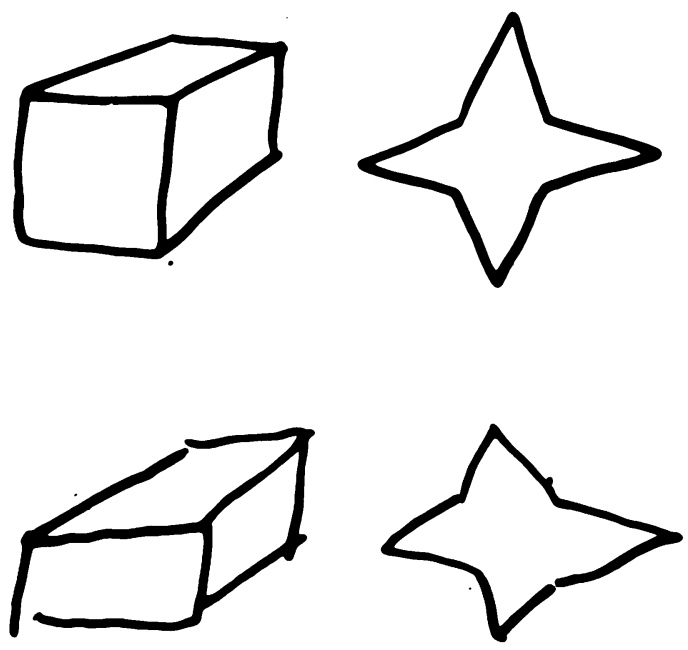

Fig 2 FRA's copies of a cube and a star. capacity to recognise visually presented objects was entirely unaffected by increasing the perceptual demands of the task. Taken together these results indicate preservation of FRA's apperceptive abilities. We would argue that his object recognition difficulties are not the consequence of impairment in the development of an adequately structured percept.

Visual Knowledge (associative Agnosia) Tests

Test 1. Picture Recognition and Word Recognition A picture and word recognition test was compiled from Zinkin and Birtchnell's ${ }^{27}$ stimulus material. Forty clear line drawings of objects were used. In the visual condition the pictures were presented singly and he was required to name them or

(a)

(c)
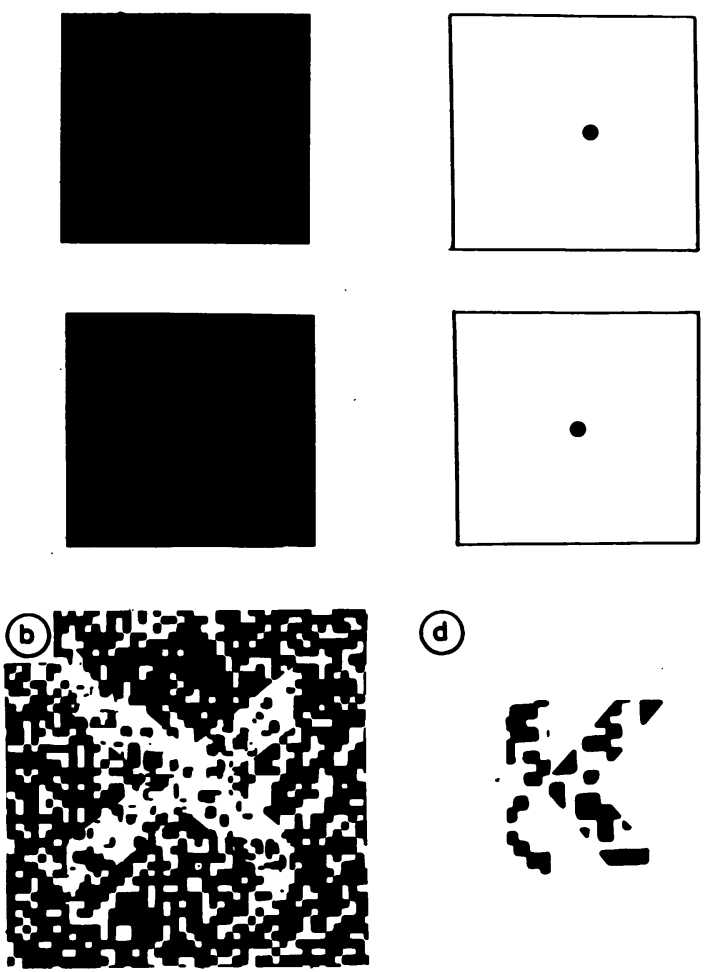

(d)

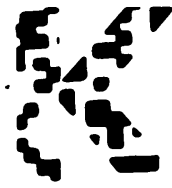

Fig 3 (a) Efron's shape discrimination stimuli. (b) Example of shape detection stimuli, (c) Examples of position discrimination stimulus, (d) Example of fragmented letter. 

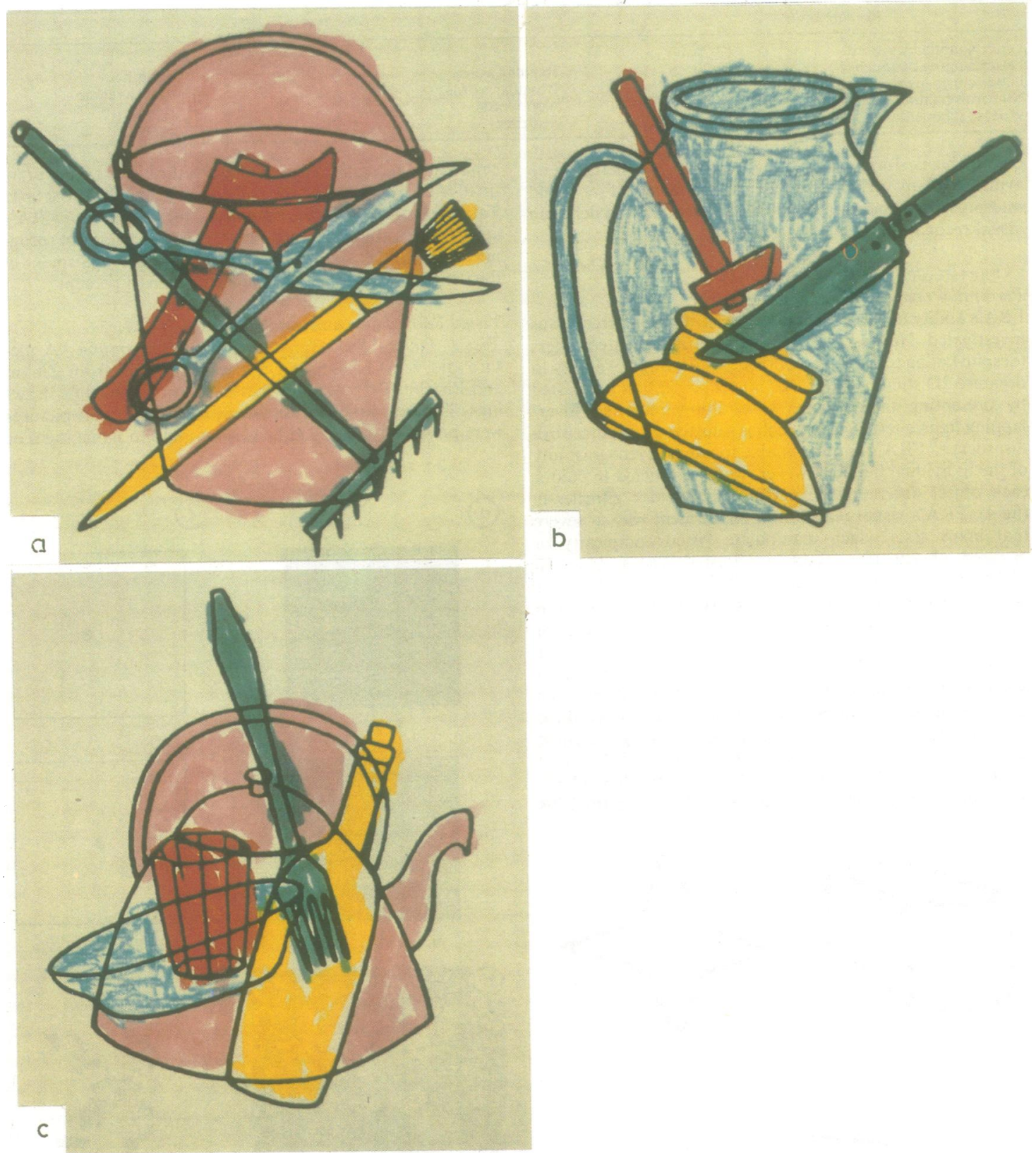

Fig 4 FRA's attempt to colour the individual objects in Poppelreuter's overlapping figures.

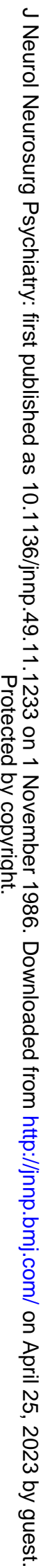


Table 3 Picture recognition and word recognition

\begin{tabular}{lll}
\hline & Picture & Word \\
\hline$(1)$ & $20 / 40$ & $40 / 40$ \\
(2) & $22 / 40$ & $39 / 40$ \\
\hline
\end{tabular}

identify them by description or function. In the auditory condition he was asked to define the same 40 object names. The visual and auditory conditions were tested in an ABBA design. The items which were presented in the first half of the visual condition were presented in the second half of the auditory condition and vice versa. FRA attempted this task on two occasions. A lenient scoring criterion was used and responses were accepted as correct if there was reasonable evidence that the core concept had been conveyed. There was a significant error rate on the visual condition. Unlike reported cases of "optic aphasia" 28 there was no evidence of perseverative responding. His errors consisted of semantic approximations and of complete failures to recognise items. His error rate was similar on the two test occasions. He also showed consistency on the items he failed to recognise $Q=0.7\left(X^{2}=6.45, p<0.02\right)$ suggesting that his impairment was not one of access to semantic representations. On the auditory condition his performance was virtually error-free (table 3). These findings establish that FRA has a visual recognition deficit of a degradation type with intact knowledge of the same information presented in the auditory verbal domain.

Test 2. Picture Word Matching The aim of this test was to document FRA's recognition of a very high frequency visual vocabulary and at the same time to explore the possibilities of category specificity. The test stimuli consisted of arrays of five realistic coloured pictures of animals, foods or objects taken from the Ladybird series of books for very young children (see reference 29). The three stimulus categories were tested in a $3 \times 3$ Latin square. Recognition was tested by requiring FRA to point to a named stimulus. Twenty trials were given on each five-item array. The percentage correct for each category is shown in table 4 . It is clear that his performance is less than perfect even on this exceptionally simple task. There was a weak category effect (chi-square $=6.9, \mathrm{p}<0.05$ ).

Test 3. Probed Visual Knowledge More detailed knowledge of visual representation of animals and of objects was
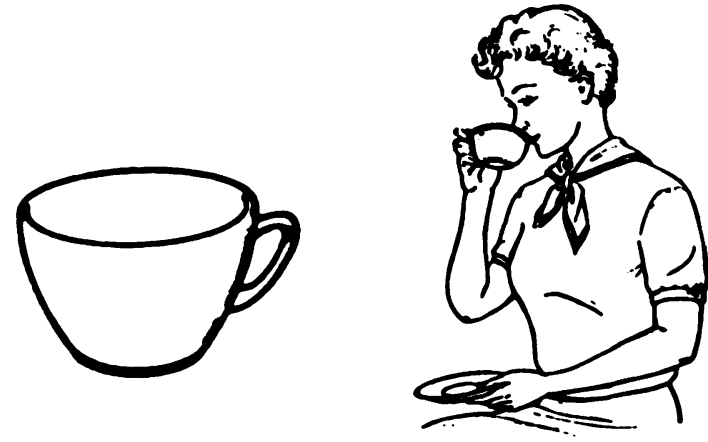

Fig 5 Example of simple and complex stimulus.
Table 4 Picture word matching No. correct

\begin{tabular}{ccc}
\hline Objects & Foods & Animals \\
\hline $45 / 60$ & $52 / 60$ & $55 / 60$ \\
\hline
\end{tabular}

assessed using a probe technique (described in full in reference 7). Triplets of coloured drawings were presented and FRA was asked to point to a picture having a particular property. The distractor items were animals and objects which did not have the property in question. The number correct for each type of probe, together with the mean score for control group, are given in table 5. FRA's scores were well below those of the controls on all types of probe.

Test 4. Probed Visual Knowledge Our aim in this test was to probe knowledge of attributes of animals and objects using both auditory and visual presentation. Triplets of black and white photographs of animals and of common household objects were assembled. There were 15 sets of stimuli in both animal and object versions. In the animal version FRA was asked to point first to the largest and secondly to the smallest (for example elephant, monkey, camel). In the object version FRA was asked to point first to the heaviest and then to the lightest item (for example drill, spectacles, jug). The auditory version was identical except that the names of the stimuli were spoken. On both visual versions of this test FRA's performance was very weak and significantly below the level of the worst control subjects on this test. His very satisfactory scores on the auditory version provide further evidence on the modality specificity of his deficit (table 6).

Test 5. Visual/Visual Matching of Objects This test was devised in order to establish whether FRA's comprehension deficit was entirely within the visual domain or the consequence of impairment in transcoding between visual and verbal knowledge systems ("optic aphasia"). A visual/visual object matching test was devised. Forty pairs of common objects were selected so that the members of each pair were physically dissimilar but had a common function and name (for example two types of razor, two types of jug). FRA was tested with arrays of five objects in two conditions. First, he was asked to match an object with its pair and secondly to match the spoken name to the object. The two conditions were tested in an ABBA/BAAB design. He was given 10 trials for each array, each stimuli being probed twice. Items that were in the visual/visual condition for the first half of the experiment were tested in the verbal/visual condition in the second and vice versa.

He was as impaired on the visual/visual condition (46/80 correct) as in the verbal/visual condition ( $43 / 80$ correct). This establishes that he has an object recognition deficit within the visual domain that is not exacerbated by transcoding between visual and verbal domains, rather than being worse on the verbal/visual condition as would be expected if he were an optic aphasic. ${ }^{28}$

Test 6. Visual/Visual Matching of Pictures Our aim in this test was to replicate the findings of Test 5 , that visual/visual matching was impaired, using pictorial material. Thirty pairs of line drawings were selected, the majority being from published children's picture vocabulary tests (for example, 
Table 5 Visual recognition (Probed)

\begin{tabular}{|c|c|c|c|c|c|}
\hline & \multicolumn{3}{|c|}{ Animals } & \multicolumn{2}{|c|}{ Objects } \\
\hline & Animal? Bird? & English? Dangerous? & Largest? Colour? & Kitchen? Man? & Metal? Heaviest? \\
\hline $\begin{array}{l}\text { FRA } \\
\text { Controls mean }(n=25)\end{array}$ & $\begin{array}{l}16 / 20 \\
19 \cdot 9\end{array}$ & $\begin{array}{l}14 / 20 \\
19 \cdot 8\end{array}$ & $\begin{array}{l}12 / 20 \\
19 \cdot 4\end{array}$ & $\begin{array}{l}15 / 20 \\
19 \cdot 0\end{array}$ & $\begin{array}{l}14 / 20 \\
18 \cdot 5\end{array}$ \\
\hline
\end{tabular}

Table 6 Visual and auditory recognition (Probed)

\begin{tabular}{lllll}
\hline & & Animals & & \multicolumn{1}{c}{ Objects } \\
\cline { 2 - 3 } & $\begin{array}{l}\text { Largest/smallest } \\
\text { Auditory }\end{array}$ & Visual & $\begin{array}{l}\text { Heaviest/lightest } \\
\text { Auditory }\end{array}$ \\
\hline FRA & $30 / 30$ & $19 / 30$ & $28 / 30$ & Visual \\
Controls mean $(\mathrm{n}=15)$ & $29 \cdot 2$ & $28 \cdot 4$ & $28 \cdot 5$ & $28 \cdot 1 / 30$ \\
\hline
\end{tabular}

reference 23). As in the previous experiment each pair of items was physically dissimilar but had the same name and function (for example two types of train and two types of brush) (fig 6). Arrays of five stimuli were tested under two alternated conditions: matching a picture to a picture and matching a spoken name to a picture. FRA was given 20 trials per array, each item being probed four times. Using this test material his performance on the visual/visual condition $(86 / 120$ correct) was significantly worse than on the verbal/visual condition $(101 / 120$ correct) $(\mathrm{z}=2 \cdot 7, \mathrm{p}<$ $0.05)$.

These findings replicate and extend the findings of Test 5 in that FRA's performance on the visual/visual matching test was very poor indeed. His significantly worse per-
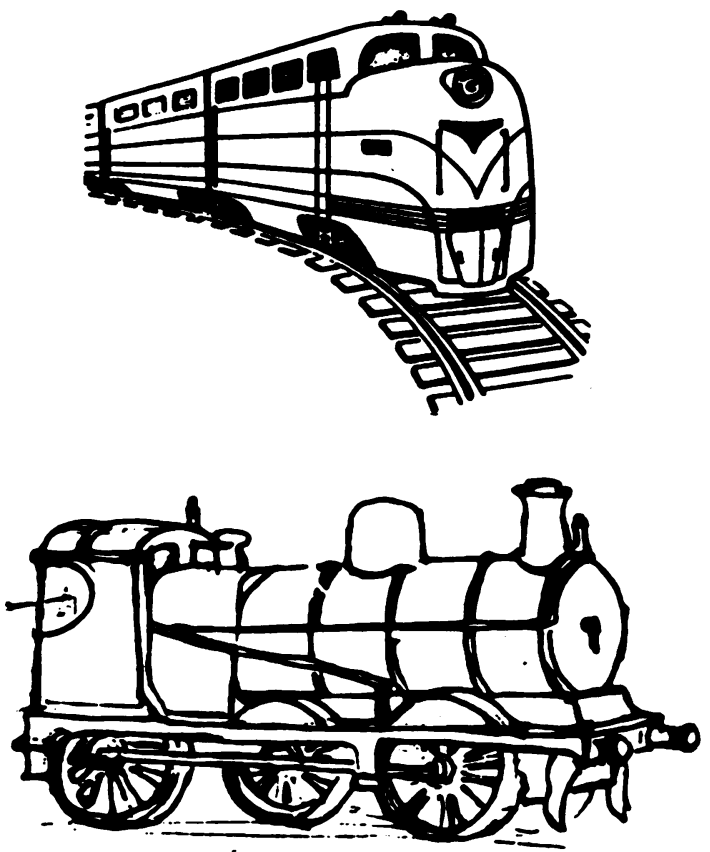

Fig 6 Example of stimulus used in pictorial visual/visual matching test. formance with visual/visual matching as compared with verbal/visual matching conclusively eliminates "optic aphasia" (for example, reference 28 ) as a contributory factor in his object recognition impairment. Rather it would appear that for FRA verbal information can actually facilitate or support visual object recognition.

\section{Discussion}

We have documented the syndrome of visual associative agnosia in a patient who showed little evidence of other cognitive deficits (apart from a total alexia). Despite having good language, visual and perceptual skills, FRA was very impaired at recognising visually presented common objects. Not only was he unable to name them, or point reliably to a named object, but he was also unable to match visually dissimilar but functionally identical objects. Indeed he was somewhat more impaired on a picture-picture matching task than on a word-picture matching task. His deficit cannot be explained either in terms of general intellectual impairment, aphasia, or as a consequence of poor transcoding between visual and verbal knowledge domains. Rather he appears to have lost his ability to recognise the meaning of visually presented objects. In this context it is of interest to note that his ability to recognise and name visual representations of actions was relatively well preserved.

As was shown on the MRI scan (fig 1) FRA's lesion was circumscribed involving a relatively small area of the occipito-temporal region of the left hemisphere. There was no evidence of any right hemisphere involvement or of any disconnection between the hemispheres in so far as the splenium and other cerebral commissures were intact. To our knowledge there is no other case of visual associative agnosia in whom there is positive evidence that the splenium is intact.

We would argue that neither the behavioural characteristics of this syndrome nor the anatomical evidence can easily be accommodated by either a discon- 
nection hypothesis ${ }^{29}$ or some form of interference hypothesis (for example, reference 31). For the former to be viable a visual/visual matching deficit should not be observed and on the latter interpretation, the facilitatory effects of verbal/visual matching tasks would not be expected. We would argue that FRA's deficit is most parsimoniously interpreted in terms of degradation of specific systems subserving visual object knowledge-visual semantics.

Turning now to the issue of contribution of the left hemisphere to object recognition: it is commonly held that both right and left hemispheres are equipotential, differing only in so far as the right hemisphere is unable to express this visual knowledge verbally. The evidence for this position is primarily based upon Sperry and his colleagues' studies of patients who have undergone complete commissurotomy for the relief of very severe long-standing epilepsy..$^{32-35}$ This position is hard to reconcile with the evidence from group studies of patients with relatively circumscribed unilateral lesions. These investigations have shown that functional knowledge of visual objects is more impaired by left than by right hemisphere lesions. ${ }^{320}$ In those single cases in whom visual associative agnosia has been a prominent feature it is once again retro-rolandic regions of the left hemisphere that are invariably damaged (for example, reference 2 ). These findings are clearly in conflict with the evidence from "split-brain" patients, a small group whose lateral specialisation of function may be atypical as a consequence of early brain damage and longstanding epilepsy. ${ }^{36}$ The present case strengthens the evidence that the integrity of regions in the posterior left hemisphere is essential for crucial and distinct components of visual object recognition.

We are grateful to Professor RW Gilliatt for permission to report the case of FRA, a patient under his care.

\section{References}

${ }^{1}$ Bender MB, Feldman M. The so-called "visual agnosias". Brain 1972;95:173-86.

${ }^{2}$ Hecaen H, Angelergues R. La Cécité psychique. Paris: Masson et Cie, 1963.

${ }^{3}$ De Renzi E, Scotti G, Spinnler H. Perceptual and associative disorders of visual recognition: relationship to the side of the cerebral lesion. Neurology (Minneap) 1969;19:634-42.

${ }^{4}$ Lhermitte F. Chedru F, Chain F. A propos d'un cas d'agnosie visuelle. Rev Neurol (Paris) 1973;128:301-22.

${ }^{5}$ Mack JL, Boller F. Associative visual agnosia and its related deficits: the role of the minor hemisphere in assigning meaning to visual perceptions. Neuropsychologia 1977;15:345-9.
${ }^{6}$ Pillon B, Signoret J-L, Lhermitte F. Agnosie visuelle associative: Role de l'hémisphère gauche dans la perception visuelle. Rev Neurol (Paris) 1981;137:831-42.

${ }^{7}$ Warrington EK. The selective impairment of semantic memory. Q J Exp Psychol 1975;27:635-57.

${ }^{8}$ Newcombe F, Ratcliffe G. Agnosia: a disorder of object recognition. In: Michel F, Schott B, eds. Les syndromes de disconnexion calleuse chez l'homme. Lyon: Collogue International de Lyon 1974:317-41.

${ }^{9}$ Benson DF, Segarra J, Albert ML. Visual agnosiaprosopagnosia. Arch Neurol 1974;30:307-10.

${ }^{10}$ Taylor AM, Warrington EK. Visual agnosia: a single case report. Cortex 1971;7:151-61.

${ }^{11}$ Davidoff J, Wilson B. A case of visual agnosia showing a disorder of pre-semantic visual classification. Cortex 1985;21:121-34.

${ }^{12}$ Hecaen H, Goldblum MC, Masure MC, Ramier AM. Une nouvelle observation d'agnosie d'objet Deficit de l'association ou de la categorisation, specifique de la modalité visuelle. Neuropsychologia 1974;12:447-64.

${ }^{13}$ Warrington EK. Recognition Memory Test. Windsor, Berks: NFER-Nelson Publishing Co, 1984.

${ }^{14}$ McKenna P, Warrington EK. The Graded Naming Test. Windsor, Berks: NFER-Nelson Publishing Co. 1983.

${ }^{15}$ Newcombe F, Oldfield C, Wingfield R. Object naming by dysphasic patients. Nature 1964;207:1217-8.

${ }^{16}$ McCarthy R, Warrington EK. Category specificity in an agrammatic patient: The relative impairment of verb retrieval and comprehension. Neuropsychologia 1985; 23:709-27.

${ }^{17}$ Coughlan AK, Warrington EK. Word-comprehension and word-retrieval in patients with localised cerebral lesions. Brain 1978;101:163-85.

${ }^{18}$ Schonell FJ. Backwardness in the Basic Subjects. Edinburgh: Oliver \& Boyd, 1942.

${ }^{19}$ Warrington EK. Visual deficits associated with occipital lobe lesions in man. In: Chagas G, Gattass R, Gross C, eds. Exp Brain Res Suppl. 11:1986.

${ }^{20}$ Warrington EK, Taylor AM. The contribution of the right parietal lobe to object recognition. Cortex 1973;9:152-64.

${ }^{21}$ Whiteley AM, Warrington EK. Prosopagnosia: A clinical, psychological and anatomical study of three patients. J Neurol Neurosurg Psychiatry 1977;40: 395-403.

${ }^{22}$ Sanders HI, Warrington EK. Memory for remote events in amnesic patients. Brain 1971;94:661-8.

${ }^{23}$ Dunn LM. Peabody Picture Vocabulary Test: Revised Edition: Windsor, Berks: NFER-Nelson Publishing Co. 1959.

${ }^{24}$ Dunn ML, Dunn LM, Whelton C, Pintille D. British Picture Vocabulary Scale. Windsor, Berks: NFERNelson Publishing Co. 1982.

${ }^{25}$ Poppelreuter W. Zur Psychologie und Pathologie der optischen Wohr nehmung. Ztschr ges Neurol Psychiat 1923;83:26-152.

${ }^{26}$ De Renzi E, Spinnler $H$. Visual recognition in patients with unilateral cerebral disease. J Nerv Ment Dis 1966;142:513-25.

${ }^{27}$ Zinkin S, Birtchnell J. Unilateral electroconvulsive therapy: its effects on memory and its therapeutic efficiency. Br J Psychiatry 1968;114:973-988. 
${ }^{28}$ Beauvois MF. Optic Aphasia: a process of interaction between vision and language. Phil Trans $R$ Soc Lond B298 1982:35-47.

${ }^{29}$ Warrington EK, Shallice T. Category specific semantic impairments. Brain 1984;107:829-53.

${ }^{30}$ Geschwind N. Disconnexion syndromes in animals and man. Brain 1965;88:585-644.

${ }^{31}$ Kinsbourne M. Mechanisms of hemispheric interaction in man. In: Kinsbourne M, Smith WL, eds. Hemispheric disconnection and cerebral function. Springfield, Illinois: Charles C Thomas. 1974.

${ }^{32}$ Sperry RW. Cerebral dominance in perception. In: Young FA, Lindsley DB. eds. Early experience in visual information processing in perceptual and reading disorders. Washington DC: National Academy of Science
1970:167-78.

${ }^{33}$ Sperry RW, Gazzaniga MS, Bogen JE. Interhemispheric relationships: The neocortical commissures syndromes of hemisphere disconnection. In: Vinken PJ, Bruyn GW, eds. Handbook of Clinical Neurology, Amsterdam: North-Holland Publishing Co. 1969.

${ }^{34}$ Sperry RW, Zaidel E, Zaidel D. Self recognition and social awareness in the disconnected minor hemisphere. Neuropsychologia 1979;17:153-6.

${ }^{35}$ Beaumont JG. The split-brain studies. In: Beaumont JG, ed. Divided Visual Field Studies of Cerebral Organisation. London: Academic Press 1982:113-28.

${ }^{36}$ Whitaker HA, Ojemann GA. Lateralisation of higher cortical functioning: A critique. Ann NY Acad Sci 1977;299:459-73. 